\title{
The why, what, and how of collection development policies
}

\author{
Carol van Zijl \\ Gold Fields Library, Vaal Triangle Technikon, Private Bag X021, Vanderbijlpark, 1900 Republic of South Africa \\ carolvz@vtt_nt.tritek.ac.za
}

\begin{abstract}
During the past decade, the issue of the collection development policy has been discussed extensively, especially in view of the new electronic resources which have become part of the stock of most libraries. In this article, the issue of the importance of such a policy in the contemporary library is discussed, especially its value as a planning, selection and decision-making tool, as well as a means of protecting the library with regard to collection management decisions. The type of information which should be included in a collection development policy is then discussed as well as the criteria which could be applied in the selection of all types of information media. A brief guide to the writing of this policy concludes the discussion.
\end{abstract}

Gedurende die afgelope dekade was daar intense belangstelling in en bespreking van die versamelingboubeleid van biblioteke, hoofsaaklik teweeg gebring deur die byvoeging van nuwe elektroniese bronne tot die biblioteekvoorraad. In hierdie artikel word die belangrikheid van 'n versamelingboubeleid in die eietydse biblioteek bespreek. Daar word verwys na die beleid se waarde met betrekking tot beplanning en keuring. Die rol van die versamelingboubeleid as besluitnemingsmeganisme en as beskermingsmaatreël word bespreek. Die inligting wat benodig word om 'n versamelingboubeleid op te stel, asook die kriteria wat toegepas word in die keuring van verskillende inligtingmedia word bespreek. Die artikel word afgesluit met 'n oorsig oor die opstel van 'n beleid.

There is a great deal of speculation regarding the value of collection development policies in the new electronic information age where the value of access to information is weighed up against ownership in one's own collection. Whilst many libraries have developed such policies, some have become outdated and unused due to the time and effort needed to update the policies regularly. Because of pressing issues regarding the acquisition of material in increasingly varied formats, it is necessary to evaluate and discuss these library policies in some depth.

The value (or lack thereof) of the collection development policies (CDP) in the information service of the 21st century needs some discussion. This will be followed by an explanation of what should be included in a CDP. Finally, the process of drawing up a collection development policy will be dealt with.

\section{Problem statement}

Not all librarians believe that CDP's merit the time and effort spent on their creation and subsequent regular revision (Snow 1996:192-193). It is necessary to view the CDP in the light of the selection, acquisition and management of collections in the libraries and information services of today and tomorrow and decide whether they are still relevant, or should be considered relics of a bygone era. Can such policies be applied usefully to the multi-format and semi-virtual environment which typifies modern libraries?

The American Library Association (Guide for written collection policy statements 1987:15) defines CDP's as

'documents which define the scope of a library's existing collections, plan for the continuing devel- opment of resources, identify collection strengths, and outline the relationship between selection philosophy and the institution's goals, general selection criteria, and intellectual freedom'.

Vogel (1996:65) sees them as sets of 'directions for the orderly selection, acquisition, and management of the materials [librarians] make available to their patrons'. CDP's are also defined as 'guidelines for decisions on the selection and retention of materials in specific subjects, to specific levels of collection depth and breadth' (Vogel 1996:65). Clayton (1993:1) sees a CDP as a

'statement of general collection building principles which delineates the purpose and content of a collection in terms relevant to both external and internal audiences'.

It can therefore be said that a CDP is a document drawn up by a specific library to provide guidelines whereby the collection is developed and managed to meet the needs of that particular user group. This policy should explain the past, present and future acquisition and collection management practices of the library for the edification of bibliographers, other library staff, users, sponsors, and anyone else who has an interest in the library in question.

Collection development refers to the selection, maintenance, acquisition and evaluation of information sources in libraries.

The people who are responsible for selecting material for libraries will be referred to as bibliographers. These might be librarians with particular subject specialisations or other members of the library's staff whose main or additional task is the selection of material for collection development. 
As a great deal of the literature covering the collection development policies relates to academic libraries, the latter will be the main focus of this article.

\section{Why should a library have a collection develop- ment policy?}

Although the collection development policy has been maligned in some library quarters, it was found in a recent survey conducted by Casserly and Hegg (1993:252) amongst academic libraries in the United States that $71.6 \%$ of the respondents indicated that they have written collection development policies. This would indicate that the CDP is not dead and still has value in the library of the $21 \mathrm{st}$ century.

It cannot be denied that Snow (1996), a vociferous opponent to the CDP, makes several valid points in his article in which he concludes that written collection development policies are just wasted words. According to him a CDP must be founded in a continuous evaluation of the library's stock and this process is difficult and confusing (Snow 1996:192). Other major weaknesses are the inflexibility of the CDP and its failure to adapt to changes in the parent institution. A further problem is the fact that revision of the policy is time-consuming and never-ending, albeit essential (Snow 1996:192-193). He also believes that CDP's have no value in the area of resource sharing in consortia, as was hoped to be the case in most of these co-operative ventures, because each library needs immediate access to certain items and therefore tends to develop its own library collection, not a communal collection (Snow 1996:193). It would be good to keep these objections and problems in mind when drawing up a CDP. This will help one not to have unrealistic expectations of the policy.

Having worked for many years in a library which lacks a CDP, the author has encountered several problems which occur when material is purchased without the guidance contained in such a policy. Without the authority of a collection development policy to stand on, it is impossible when confronted by an irate lecturer or librarian to rationalise why some material should be purchased whilst other is rejected. Faculty members and the management of the academic institution have often demanded that the library purchase items which serve the needs of only one or two users and in fact sometimes expect such material to be housed in their own offices permanently.

The collection developed rapidly in the subject areas which fell under enthusiastic and pushy faculty members and staff, whilst the more docile group failed to keep their collections in line with advances in the fields or with changes in user needs. As a result, the collection did not develop in a rational, orderly way which has led to frustration and even anger when users realise that their subject fields appear to have been ignored. Indeed, during a 1997 SERTEC evaluation at the Technikon Library, it was discovered that in one subject field only six items had been purchased over the many years in which the course had been offered. Often there has been confusion as to who is actually responsible for selecting items to ensure a balanced and current collection, with both the academia and the librarians waiting for the other sector to perform better. In the current situation where material is often available in several formats and where decisions have to be made regarding periodical subscriptions or subscriptions to electronic resources, the decision-making process has been even more complex. The need for a CDP becomes more pressing as libraries move towards access to electronic media instead of ownership of print items.

\section{Use as a planning document}

The CDP is an important planning document for the library. The reduction in funding for academic libraries appears to be a universal phenomenon, which means that available budgets have to be spent with more circumspection and care. Added to this problem is the rapid inflation in the price per item, and especially that of electronic resources. The confusing array of formats in which information is available exacerbates the problem. A policy which gives clear but simple guidelines in the selection of material would clearly be of benefit to bibliographers and would lead to them making more consistent and informed decisions (Johnson 1997:83). White and Crawford (1997: 55) advocate the use of a CDP, particularly with regard to electronic resources, in order to 'guide us in our decisions, to address faculty/student needs and concerns, and to help us plan for future changes'. Intner (1996:10) also sees the CDP as a valuable planning tool without which there will be a mismatch between the materials users are given and what they actually need.

\section{Use as a selection tool}

The process of selection of library material is complex and many bibliographers approach the task with little or no training or guidance. This could lead to haphazard growth of the collection which will over the course of time no longer support the mission of the library (Vogel 1996:65). Over- and underselection of material can both lead to a library collection which does not meet the needs of users (Carrigan 1996:274). On average, it has been found that $80 \%$ of the circulation needs in a library are satisfied by about 20\% of the library's stock (Carrigan 1996:275). Clearly much of the material purchased is seldom or never used and improved selection criteria are required. A good CDP can be used as a training document for bibliographers in the performance of their duties. This could result in more control and consistency in selection and management of the collection and could foster shared values among the selectors (Johnson 1997:85).

\section{Use as a means of protection}

Another important reason for developing a CDP is that such a document protects the library and bibliographers by 
providing them with a firm framework in which to make decisions. Hazen (1995:29) maintains that these policies 'keep us out of trouble with our users', which is certainly to be desired. Bibliographers can be subjected to unethical and unreasonable pressures regarding certain material. Groups might strive to impose their ideologies or censorship on the library or try to get the library to purchase material which is irrelevant to the general user population. Patrons can often be unreasonable when their gifts to the library are not accepted. Weeding of material is also sometimes a bone of contention which is questioned by users (Johnson 1997:88). The CDP can be used to justify all these practices to those who question decisions regarding the management of the collection. Not only will the CDP provide protection to the library, but it could also be used as a tool to communicate the collection development plan to outside bodies and can be used as an aid to get additional funding for library programmes (Vogel 1996: 67): It would be a good idea to disseminate the completed policy as widely as possible to inform others about decisions contained in it.

\section{Use as a decision-making tool}

The proliferation of electronic formats available have made the task of selection even more complex than in the past, and provides an additional reason for drawing up a CDP to assist in collection development and management. A selection tool for the selection of Internet resources and for choosing between the various and exceedingly expensive online databases and CD-ROM's available would be very valuable to selectors and bibliographers.

It would be naive to see the CDP as a panacea for all the problems which arise in collection management and selection of material. However, having guidelines to follow and criteria to apply does carry many benefits for a library and explains a great deal to anyone who has a say in the way in which the collection is developed.

\section{What should be included in a collection develop- ment policy?}

CDP's are created by specific libraries and information services to explain the collection development practices of that library. It is difficult to be prescriptive regarding the contents of the policy as the environment of each library is unique. The library's mission, subject coverage and the composition of the user body largely dictate what should be included in the CDP. There is even some speculation as to whether there should be one comprehensive policy or a collection of separate policies for the different formats in which information is provided today (White \& Crawford 1997:54). Certain issues are usually considered for inclusion in collection development policies. These include the following:

- The mission and goals of the library and the parent institution is usually given as part of the policy's in- troduction. Intner (1996:10) sees the translation of the mission and goals of the institution and the needs of its users into a set of long-range collection goals and objectives as the most important feature of a real CDP. In her view, this leads to all other aspects of collection development like allocations from the budget, target collecting levels and also the selection of individual titles.

- It is also useful to include the purpose of the CDP in the introduction. This could include the reason for the creation of the policy, a discussion of the intended users or readership of the policy, how it is to be used and what authority the policy carries (Clayton 1993:1).

- The composition and nature of the user community or clientele is also important. Clayton (1993:1) suggests that unusual and unexpected features of the user group served be referred to, as well as specific needs and possible differential treatment of certain classes of users. It is particularly important to explain how much and what level of research is undertaken by users as this is of crucial importance in selection of material and in development of the collection.

- An evaluation of the collection - past, present and future - is important. This section could include the background or history of the collection, and what strengths and gaps are encountered (Johnson 1997:84). One could include an overview of the categories of materials which make up the collection such as monographs, journals, electronic media and audiovisual material and any distinguishing features of the collection. The desired levels of collection depth and breadth should be given as well, to provide a meaningful planning document for the library. This section is usually subject-area specific and will be dealt with in more detail further on.

- It would be valuable to include a section clarifying what type of access, is provided to the collection. To access electronic media some kind of hardware is always required. The type, availability and limitations of user access would have a definite influence on the choice of format which should be preferred when making decisions in collection development. In many cases, some or all categories of users are denied direct access to electronic resources. Increasingly, resources are shared amongst members of consortia, which means that although the resources of the consortium are available to all members, the access is not immediate. The holdings of the consortium's joint catalogues are virtually also those of a particular member library and the relationship should be explained in a CDP. Johnson (1997:85) suggests that all co-operative programmes in which the library is involved be explicitly stated in the CDP. Interlending and electronic data transfer might also need to be considered as additions to the collection. Clayton (1993:2) suggests that one include possible restrictions to interlibrary loans requests and remote 
access to electronic media in the CDP. It is also possible to include hot links (hypertext links to Internet web sites) to curriculum-related sites available on the Internet on the library's OPAC's as an additional means of providing access to information and responsibility for this could be spelt out in the policy.

- It is common practice to include in a CDP the way in which funds are allocated from the library's budget. Many libraries have separate budgets for different types of media, such as monographs, serials, electronic media and audiovisual media. Decisions need to be made as to whether this would have value in one's own circumstances or whether one fund would be possible. Another consideration is how the budget could be divided between the subject areas covered, or the departments at the institution. Many libraries use formulae whereby the number of lecturers in the departments concerned, the number of postgraduate students served, gaps in the present collection, average book price by subject, new courses offered, total number of students in the department and other aspects are taken into consideration. The way in which funds are to be allocated should be specified to help bibliographers in their selection activities and also to explain to outside parties how funds are spent. Clayton (1993:2) suggests that the expected ratio between expenditure on serials and on monographs should be included. This ratio should also include the proportion of the budget to be spent on electronic media and databases.

- Of great value to bibliographers would be clear guidelines as to the criteria which should be applied in the selection of material and also in the choice between various formats when the same information is available in different media. The following is a list of some criteria which have proven useful in the selection of all formats of material.

$\square$ Relevance and use - is the material relevant to the curricular requirements of the institution? (White \& Crawford 1997:56). Will the source be used by several departments? How large is the potential readership or usership of the source? In determining relevance, it is essential to have a clear understanding of the user population of the library.

$\square$ Redundancy - is the material or similar material available in another format in the library (White \& Crawford 1997:56) or is it already in the collection of a nearby library or other members of the consortium to which the library belongs?

- Relationship to the existing collection - does the item complete, supplement, duplicate or supplant items already in the collection? (Oise/UT ... 1995:3) What other materials are available on that subject? Does that item fill a gap in the collection, or is it merely a rehash of information already available?

$\square$ How authoritative is the author, the issuing body or the publisher? $\square$ Suitability of the subject and style - is the desired level of coverage attained? Is the style appropriate for study and research at the level for which the item is intended? (Oise/UT ... 1995:3)

$\square$ The cost of the item - does the item merit its cost and what is the cost difference between the different formats in which the item is available? Is it possible to acquire information of the same standard and coverage more reasonably?

- Is the information accurate and impartial?

Is the item recent? This is particularly important when the material covers the applied sciences, technology and computer science which are constantly progressing.

$\square$ Presentation - is the information presented in an accurate, clear, logical manner? Does it adhere to high standards with regard to format, content and literary merit? Does it have aesthetic appeal? Are figures and illustrations adequate?

$\square$ In the case of periodicals, is the item indexed in major indexing and abstracting journals and databases?

$\square$ Are there any features which make the item unique? Is the approach to the subject matter original? Do the illustrations have particular merit? What makes the item under consideration more valuable than other similar items?

$\square$ Language - what is the language in which the item is written? Will the users be able to understand the text? Is the language of a standard appropriate to the education level of potential users?

Is the item listed in standard guides? (Reinert/Alumni ... 1996:6)

a Timeliness - is the material appropriate for the present time, is the information current and does the item fit in with the climate of the times? (Vogel 1996:73)

- There are certain criteria which are applicable especially to the selection of electronic resources.

$\square$ Ease of use (White \& Crawford 1997:56) - is the electronic resource user-friendly? Can it be used with the minimum of training? Are there clear on-screen instructions?

$\square$ Accessibility of resource to users - are there problems in providing access to users or restrictions in the licensing contract which will deny use to certain users? Are provisions made for only a restricted number of concurrent users?

$\square$ What kind of vendor support is offered (White \& Crawford 1997:57) both by way of a help desk and by way of technical assistance?

$\square$ When identical material is available in print and electronic format, do the benefits of using the latter weigh up favourably against the added cost (which might include additional hardware) of choosing the non-print format? Will less users have access to the electronic format than to the print version or will it be 
possible to reach more users, possibly at remote locations?

$\square$ Is additional hardware and equipment necessary to use the electronic resources under consideration, and if so would the benefits outweigh the expense incurred? Johnson (1997:96) warns of hidden costs such as continuing leases, furniture, search engines, loaders, connect and telecommunication time, storage, additional cabling and wiring, upgrades, documentation and continuing technical support. The CDP must make clear how these financial obligations will be met.

- How much staff and user training would the new material necessitate?

口 Is the technology involved standardised, or would the institution's information technology department struggle to install the item and maintain it?

Is the interface attractive and informative?

$\square$ Longevity - how long will the item remain relevant (White \& Crawford 1997:57)? Has the equipment needed to run the programmes been tried and tested, or is there a danger that in time the items will no longer be readable?

In the case of electronic journals, will the publishers continue to provide access to those issues to which you subscribed even after you have cancelled the subscription? Are these journals archived adequately?

$\square$ The speed of retrieval is important in the selection of electronic resources including online or Internet resources.

- In the case of full-text databases in particular, how sophisticated is the search function? Is it possible to truncate, indicate proximity of terms and does the programme show how relevant the article is by including a way of indicating how often the search terms occur in the document?

Are the publishers of the electronic resources willing to negotiate with regard to the licensing agreement to accommodate the particular needs of your library? Will they allow remote access to electronic resources and does the problem of specifying the number of concurrent users apply?

$\square$ With bibliographic databases, are all those journals which are considered to be core journals in the field indexed? How many of the journals indexed are held in the library?

$\square$ Even with online electronic resources such as those chosen from the Internet, bibliographers must use some of these criteria in the selection of sites which will be linked to the library's OPAC's or Intranet (Web site created locally to provide links to important Internet resources).

- Responsibility must be clearly assigned in the CDP. Who is responsible for selecting electronic resources and for negotiating and signing contracts (Johnson 1997:87)? Who is responsible for selection of other items? If faculty members and other users undertake selection, what control does the library exercise over these recommendations and who makes the final decision (Clayton 1993:2)?

- Clarity regarding duplicate copies of items must be given. Will the library purchase only one copy of each item? Under which circumstances will duplicates be acquired?

- How does the library handle gifts? Criteria for the acceptance and rejection of gifts should be clearly given. The procedure regarding the disposal of rejected gifts must also be included to obviate problems with the donor.

- The library's weeding policy should be clarified. This should include information regarding who is responsible for weeding, what criteria are used for deciding which material should be discarded, how regularly the weeding is performed and what is done with the discarded material (Clayton 1993:3). Linked to this is the library's policy regarding which missing or discarded material will be replaced and under which circumstances this will be considered. It is important to remember to remove pointers or 'hot links' to Internet or World-Wide Web resources linked to the library's catalogue when these are redundant or the addresses have become inoperable (Vogel 1996:75). Responsibility and procedures for this could be included in the CDP.

- It might be valuable to include the library's policy on matters of censorship and intellectual freedom, should this be considered appropriate or relevant to the type of collection concerned.

- The categories of material which will be excluded from the collection could be specified, such as material in certain formats, price categories, and languages (Clayton 1993:3).

- To ensure that the collection development policy is relevant and appropriate, a policy regarding the regularity of, and procedure for evaluation of the collection should be included.

- Clear guidelines regarding the revision of the policy are essential to ensure that the CDP does not become obsolete and irrelevant.

\section{How to compile a collection development policy}

The process of drawing up a collection development policy is not an easy one and merits great care and thought if it is going to warrant the effort involved in its creation.

\section{Who should be involved?}

It is unusual for a single person to have sole responsibility for drawing up the policy. Firstly, several sections in the library are involved in managing the collection and secondly, without the interest and collaboration of all members of staff concerned with the collection, the CDP would indeed be wasted words. All those who will have to implement the 
policy will have to be involved in its creation. Should an individual person be obliged through force of circumstances to write a CDP, it is essential that the input of all other interested parties also be acquired before the document is accepted as policy in order to incorporate the perspectives of all. This is the only way to arrive at a balanced and mutually acceptable policy.

When a working group is given the responsibility of drawing up the policy, the members of the group must be those who are enthusiastic about the project and the team leader should have the knowledge and leadership skills to see to the smooth progress of the project. Johnson (1994:3) recommends that there be faculty participation from the outset as this will improve understanding between the academic departments and the library, and would possibly result in greater co-operation. The optimum size for a work group of this type is between five and nine members (Johnson 1997:99).

\section{Getting started}

As this is a long-term project, Johnson (1994:3) suggests that the team draws up a timetable whereby the steps in the process are scheduled and a completion date is projected. From the outset, responsibilities should be assigned and a tentative outline for the document should be drawn up. It is vitally important that some of the members of the team, or possibly the team leader, read as much of the literature regarding CDP's as possible to approach the project in a logical and well-informed way. The Guide for written collection policy statements (1996) is particularly useful as a starting point.

Many libraries in the United States, Australia, Great Britain and elsewhere have made their CDP's available on the World-Wide Web. It would be of enormous value to download or print as many of these as possible. These can give one an idea of what would be useful in one's own CDP. Where sections of these CDP's are applicable, they could, within the limits of copyright restrictions, be transferred and used or adapted to one's own policy. This author could unfortunately not find any CDP's of South African libraries on the Web. These would have been particularly valuable as local conditions differ somewhat from those of other countries.

The goals and objectives of the library and of the parent institution should be clearly stated and objectives for the CDP should be drawn up in support of these goals and objectives. The user population should also be studied and clearly defined to ensure that the policy meets the needs of all users. Johnson (1994:4) recommends that a study be made of all existing formal and informal policies currently guiding collection development in the library and any other documentation in existence which could be included in the policy.

\section{Choosing a style of presentation}

If the policy is not to become a white elephant which noone uses in future, the writers of the policy must ensure that the style is simple and clear. Make use of many headings to help future users find the sections they are looking for easily. Pay careful attention to the layout of the document it must be pleasing and orderly in appearance. Beware of making the document too theoretical as this will certainly condemn the policy to a life in a filing cabinet, only to be dusted off when new bibliographers join the staff.

In order to combat the problem of CDP's being too rigid, it is important that the wording provide for as much flexibility as possible. When feasible, use descriptions which encompass all formats of information and resources so that these can be interpreted to apply to any new or evolving formats, materials and collection development methods (Hazen 1995:31).

Decide whether the classed analysis approach like the Conspectus developed by the Research Libraries Group (RLG) (Ferguson, Grant \& Rutstein 1988:198) will be used or whether a more narrative style of writing will better serve the needs of the library. Possibly a combination of the two methods could be used. The Conspectus, which was originally developed to help with interlibrary loans, provides a framework for describing the collection in terms of current and intended levels of collection in specific subject classes. Five collecting levels are identified in the Conspectus (Vogel 1996:69). These are specified in the VT university libraries collection development policy (1995:1) as:

- 'Minimal level - A subject area in which few selections are made beyond very basic works

- Basic level - A highly selective collection which serves to introduce and define the subject and to indicate the varieties of information available elsewhere. It includes major dictionaries and encyclopaedias, selected editions of important works, historical surveys, important bibliographies, and a few major periodicals in the field

- Study level - A collection which supports undergraduate or graduate course work, or sustained independent study: that is, which is adequate to maintain knowledge of a subject required for limited or generalised purposes, of less than research intensity. It includes a wide range of basic monographs, complete collections of the works of important writers, selections from the works of secondary writers, a selection of representative journals, and the reference tools and fundamental bibliographical apparatus pertaining to the subject.

- Research level - A collection which includes the major published source materials required for dissertations and independent research, including materials containing research reporting, new findings, scientific experimental results and other information useful to researchers. It also includes all important reference works and a wide selection of specialised monographs, 
as well as an extensive collection of journals and major indexing and abstracting services in the field.

- Comprehensive level - A collection in which a library endeavours, as far as is reasonably possible, to include all significant works of recorded knowledge (publications, manuscripts, other forms) for a necessarily defined field. This level of collection intensity is that which maintains a "special collection"; the aim, if not the achievement, is exhaustiveness.'

The required collection levels could be specified in the CDP as an aid to bibliographers and as an explanation to users. This method is used in many CDP's and appears to be a valuable tool in describing the present collection and the desired depth of coverage for the future.

To extend this method to electronic resources as well, Johnson (1997:92) suggests that categories of information genre be developed and that these collection depth indicators then be assigned to the various genres to indicate to which extent the various formats will be developed. She suggests that these genres could include bibliographic information, numeric and statistical data, applications software, textual files, courseware, sound files, image files and multimedia.

Alternately, one could classify electronic information by 'type of resource', which could include reference resources (directories, dictionaries and OPAC's), monographs, journals or serials, discussion groups (e.g. listserv lists and newsgroups), numeric files, gopher servers, gateways and network servers, archives, video conferences, games, government publications and library staff resources (Johnson 1997:93).

\section{Writing the policy}

The actual writing of the CDP can now commence. This section is based largely on the ideas of Johnson (1994:2-5).

In the introduction and overview sections one should include statements regarding who is responsible for the various collection management duties. The introduction should also include background information, an overview of the user population and the purpose and audience of the policy. If the conspectus approach is chosen, the collection levels of the various subject areas, or otherwise a narrative description of such levels, could be included in the introductory material. Now the body of the CDP as specified in the overview or table of contents must be written.

This could be organised in several ways. Subsections might include some or all of the following:

- subject- or department-specific subsections;

- collections housed in particular locations or branch or satellite libraries; and

- recurring collection management activities and decisions which apply to all subject areas. Matters like budgetary considerations, weeding, storage, handling of gifts and choice of electronic resources lend themselves to overarching policies.
It might also be a good idea at this stage to draw up templates which could be used as guidelines for the compilers of the subject-specific subsections of the CDP. These could take the form of checklists or questionnaires to be completed by team members in the various subject disciplines relating to their collections, needs, limitations and any other factors which are relevant in one's library. This will mean that the uniform aspects of collection management will be dealt with in all these subject areas and this will lead to a more balanced policy. These templates can be added to the policy as appendices.

Other appendices could be forms which will be used to guide decision making, especially for expensive items. These could include checklists, questionnaires or decision matrices to guide bibliographers in the evaluation of criteria (Johnson 1997:98) - especially in choices relating to electronic resources. If necessary, separate forms can be devised for the various formats which will be included in the collection.

Include in the CDP local policy relating to all relevant aspects of collection management as mentioned in the previous section.

When this stage has been completed, the project team should review and revise the draft document again and ensure that it meets the needs of the library. The templates could be distributed to the responsible persons in the various subject fields for completion, if such a path was chosen. These completed documents will then also become subsections of the CDP.

A sound practice would be to allow legal counsel to review any areas dealing with copyright, licensing agreement and other aspects which have legal implications.

Now the project team must conduct a final review of the policy to ensure that there is consistency across the subsections and that no important aspects have been omitted. After this, the policy should be officially implemented. Clear guidelines should be included for the regular revision and amendment of the policy to ensure that new developments in the field of collection management and in the library are always included in the policy.

\section{Conclusion}

There can be no doubt that the compilation of a collection development policy is an arduous and time-consuming task and that without continuous care, revision and attention the CDP could become out-of-date and useless to bibliographers, library administrators and the parent institution. If the $\mathrm{CDP}$ is not seen by all concerned as a practical guideline which is easily implementable and which aids rather than hinders selection in the multimedia collections of presentday libraries, there is clearly no point in having such a policy. 
This author has, however, experienced the haphazard and often unfair approach which develops when no-one in particular accepts overall responsibility for the management of the collection. It seems clear that a carefully drawn up and regularly revised CDP must have great value in a library.

The continuous attention to the CDP by researchers in countries throughout the world today indicates that many librarians who are involved in collection management share this view, and are trying to adapt the CDP to meet the needs of the new electronic library environment.

As budgets are diminishing and resources are becoming more expensive all the time, surely the need to exercise increasing control over the selection of library material is more important than ever. Libraries are also having to justify more and more their expenses and their need for funds to support their programmes. A well-constructed collection development policy is the ideal tool for this purpose.

There is so much uncertainty and disorganisation related to trying to function without a collection development policy that it would appear that the CDP, with all its problems, is the best option to go for in co-ordinating activites relating to collection management in libraries.

\section{References}

Carrigan, D.P. 1996. Collection development - evaluation. Journal of academic librarianship, 22(4):273-278.

Casserly, M.F. \& Hegg, J.L. 1993. A study of collection development personnel training and evaluation in academic libraries. Acquisitions: practice \& theory, 17:249-262.

Clayton, P. 1993. ACLIS guidelines for the preparation of a collection development policy. [Online]. Available: http:www. nla.gov.au/aclis/cdpguide.html
Ferguson, A.W., Grant, J. \& Rutstein, J.S. 1988. The RLG Conspectus: its uses and benefits. College \& research libraries, 49:198.

Guide for writing a bibliographer's manual. 1987. Chicago: American Library Association.

Guide for written collection policy statements. 1996. Chicago: American Library Association.

Hazen, D.C. 1995. Collection development policies in the information age. College \& research libraries, 57:29-31.

Intner, S. 1996. The ostrich syndrome: why written collection development policies are important. Technicalities, 16(7):810.

Johnson, P. 1994. Writing collection development policy statements: getting started. Technicalities, 14(10):2-5.

Johnson, P. 1997. Collection development policies and electronic information resources. In Collection management for the 21st century: a handbook for librarians; edited by G.E. Gorman, R.H. Miller. Westport, Conn.: Greenwood Press.

Leonard, B.G. 1994a. Collection management in Australian academic libraries: an American perspective. Library acquisitions: practice \& theory, 18(2):147-156.

OISE/UT library collection development policy. 1995. [Online]. Available: http://www.oise.utoronto.ca/library/colldev/ policy l.html

Reinert/Alumni Memorial Library: collection development policy. 1996. [Online]. Available: http://reinert.creighton.edu/ coldev1.htm

Snow, R. 1996. Wasted words: the written collection development policy and the academic library. Journal of academic librarianship, 22:191-194.

Vogel, K.D. 1996. Integrating electronic resources into collection development policies. Collection management, 21(2):65-76.

VT university libraries: collection development policy. 1995. [Online]. Available: http://www.lib.vt.edu/facilities/colldev/ coll_dev_policies/COLLEVEL.html

White, G.W. \& Crawford, G.A. 1997. Developing an electronic information resources collection development policy. Collection building, 16(2):53-57. 